\title{
Lasers bend beams for desktop X-ray source
}

\section{Jim Giles}

The Advanced Photon Source in Argonne, Illinois, occupies an area the size of a sports stadium. But if Ronald Ruth is right, this tool, widely used in materials and biomedical science, can be shrunk down to fit on a desk.

Ruth's idea, which he outlined on 16 April, only exists on paper - for now. Yet it has already attracted $\$ 7$ million in support funding from the US National Institute of General Medical Sciences, which hopes that the device will help in the study of biologically important molecules. Ruth's background as an accelerator physicist at the Stanford Linear Accelerator Center in California also lends the project some credibility, synchrotron experts say.

Synchrotrons generate beams of highenergy X-rays, which can be used to determine the structure of proteins and materials. The beams are derived from electrons accelerated to within a whisker of the speed of light. These electrons are stored in large rings, some with diameters of hundreds of metres. Such devices are typically shared by hundreds of regular users, and demand for time on them often outstrips supply.

Ruth's alternative, launched at the Keystone Symposia on Structural Genomics in Snowbird, Utah, stores electrons at far lower energies - about $25 \mathrm{MeV}$ compared with $7 \mathrm{GeV}$ in the Argonne device - in a rounded rectangle just one metre long. The key difference is in the way it generates its X-raybeam.
$\mathrm{X}$-rays are emitted when fast-moving electrons change direction. Originally, synchrotrons made use of the radiation generated as electrons were forced round the curved storage rings, but state-of-the-art devices use magnets to insert additional short deflections in the path of the particles.

Ruth intends to deflect the electrons using a fixed pattern of laser light, formed by bouncing a laser beam back and forth in a cavity that lies along the straight section of the mini-synchrotron's storage ring. This should bend the particles through tighter curves than is possible using magnets.

Ruth claims that this will produce X-rays with energies in the range of $5-35 \mathrm{keV}$, which should allow them to be used in many of the studies currently carried out at shared facilities. But the brightness of the beam will be orders of magnitude below that needed for some experiments, such as work on the crystal boundaries below the surface of metals.

Some researchers say that they will believe Ruth's idea when they see it in action. Many designs look better on paper than they work in practice, says Janos Hajdu, a biochemist at Uppsala University in Sweden, who uses synchrotron radiation to study protein structure. "But I'll have one if he can make it happen."

The proposed machine, known as the Compact Light Source, will be marketed by Lyncean Technologies of Palo Alto, California, a company co-founded by Ruth. He is reluctant to put a price on the device, but says it is likely to cost in the region of a few million dollars.

Although the notion of universities owning their own synchrotron is enticing, potential users say that the device could have drawbacks. Critics note that the slowermoving electrons will interact with each other and the walls of the device, limiting the time they can be stored, and for which X-rays can be produced, to a fraction of a second.

But Ruth says that electrons can be added to the ring while it is operating, allowing the device to produce a continuous beam of $\mathrm{X}$-rays. If he is correct, Ruth's design might offer an advantage over other X-ray sources that use a laser to bend electrons, as, so far, these can only produce bursts of radiation. He adds that Lyncean is building a prototype that should start generating $\mathrm{X}$-rays early in 2005.

\section{Side effects leave smallpox vaccine in limbo}

\section{Erika Check, Washington}

Trials of a new version of the smallpox vaccine have been halted because of a rare side effect, raising concerns about the vaccine's suitability for widespread use.

On 13 April, Acambis in Cambridge, UK, said that it had stopped recruiting patients into a large clinical trial of the vaccine because three people in the trial had developed myopericarditis - swelling of the heart muscle and surrounding tissue.

The US government has already ordered millions of doses of the new vaccine, called ACAM2000. But the latest finding makes it unlikely that it will be given to civilians unless there is an emergency.

The United States began a civilian vaccination programme in 2002. So far, about 40,000 emergency workers have been given an older version of the vaccine to prepare them for a bioterrorist attack. But the programme has moved far more slowly than was intended, largely because of people's concerns about side effects.

Myopericarditis was not seen during the large-scale smallpox eradication campaign of the 1960s and 1970s, which used the version of the vaccine called Dryvax. But the side effect has emerged in new clinical trials of Dryvax. The US Department of Defense reports that, since December 2002, 77 of 615,149 military workers who took Dryvax developed myopericarditis. In the Acambis trials, which compared Dryvax with
ACAM2000, both versions of the vaccine seemed to cause the condition.

"It is still a big question whether this is something really new or whether these things happened before, but were not noted," says Anthony Fauci, director of the National Institute of Allergy and Infectious Diseases in Bethesda, Maryland.

Fauci says that ACAM2000 could still be given to civilians in an emergency. But health officials are unsure how to continue tests of the new vaccine. It is also not clear how efforts to license the vaccine will proceed. Fauci says that it may become necessary to stockpile a milder version of the smallpox vaccine - modified vaccinia Ankara - which is also being tested. 